\title{
Melawat Ke Dunia Virtual Transformasi Guru Sejarah Biasa Menjadi Guru Memesona Abad 21 Di Masa Pembelajaran Jarak Jauh
}

\author{
I Gede Indra Pratama1, I Gusti Ayu Cahayaningsih ${ }^{2}$ \\ SMK N 1 Mas Ubud ${ }^{1}$, SMA N 1 Payangan² \\ Email: indrap590@gmail.com ${ }^{1}$, cahayaningsih57@ gmail.com²
}

\begin{tabular}{c}
\hline Artikel info \\
Keywords: \\
Transformasi, Guru Memesona, \\
Pembelajaran Jarak Jauh
\end{tabular}

Pembelajaran Jarak Jauh

Coresponden author:

Email: indrap590@gmail.com

\begin{abstract}
Abstrak. Abad 21 ditandai dengan keterbukaan teknologi komunikasi dan informasi. Setiap lapisan tidak terkecuali guru, harus beradaptasi dengan perubahan yang terjadi, guna menunjang pembelajaran yang efektif dan efesian namun tetap bermakna. Dalam situasi luring, pembelajaran bermakna dapat dilakukan secara maksimal. Namun pada situasi pandemi Covid 19 yang mengharuskan pembelajaran menggunakan sistem jarak jauh diperlukan sistem pengajaran yang menarik dan bermakna khusunya mata pelajaran sejarah. Agar pembelajaran menarik dan bermakna berjalan maksimal di masa pembelajaran jarak jauh, dibutuhkan sosok guru memesona yang memiliki kompetensi abad 21 yang dapat merangkul generasi $Z$. Kehadiran guru memesona abad 21 setidaknya dapat mengimbangi peserta didik yang "gandrung" serta menjadikan dunia maya sebagai pengganti kelas nyata mereka.
\end{abstract}

\begin{abstract}
The 21st century is marked by the openness of information due to progresive developments in communication and information technology. Every individual, including teachers, must adapt to the changes in order to support effective, efficient and meaningful learning. In offline environment, meaningful learning can be done optimally. However, during the COVID-19 pandemic that requires distance learning, teachers can still provide interesting and meaningful learning for history subjects. In order for interesting and meaningful learning to run optimally in distance learning, a charming teacher who has 21st century competence that can can embrace Generation $Z$ is needed. The presence of charming 21st century teachers can at least support the need of the students characterized by the online and internet base learning.
\end{abstract}

\section{PENDAHULUAN}

Apakah anda pernah mengikuti pembelajaran yang mudah dipahami dan menyenangkan? Pembelajaran yang efektif dan menyenangkan sangat bergantung pada kemampuan guru dalam memfasilitasi pembelajaran. Cara guru bertindak dan bekerja sangat ditentukan oleh pengetahuan, pengalaman, dan sistem kepercayaan 
terhadap pembelajaran itu sendiri. Seperti contoh sosok seorang guru yang selalu dirindukan untuk hadir di kelas, kerinduan peserta didik terhadap guru mereka dapat diterjemahkan kedalam rindu akan penampilannya, rindu akan motifasinya, rindu akan humorisnya serta rindu akan gaya mengajarnya. Dalam suasana luring guru memesona abad 21 dapat dilakukan oleh setiap guru yang ingin berusaha tampil "beda", namun bagaimana jika kondisi seperti saat ini, ditengah pandemi covid-19 yang mengharuskan pembelajaran jarak jauh (daring)?. Dan bagaimana mendiskripsikan guru memesona abad 21 itu?. Kondisi tersebut diperparah oleh minimnya interaksi guru-siswa sehingga arena guru untuk menjadikan dirinya memesona dimata peserta didik menjadi sebuah dilema. Pembelajaran berbasis digital sesungguhnya menjadi opsi "kegalaun", namun opsi tersebut kembali memunculkan permasalahan seperti; 1) peralihan dari model pembelajaran tatap muka ke model daring memerlukan waktu adaptasi bagi guru dan peserta didik; 2) peserta didik menjadi bosan karena model pembelajaran hanya memuat materi serta tugas yang harus dikerjakan dan diunggah saat itu juga; 3) tidak ada variasi interaksi antara guru dan peserta didik, interaksi hanya mengandalkan WA tanpa sekalipun tegur sapa dalam pembelajaran.Lalu langkah apa yang harus diambil para guru khususnya guru sejarah untuk menjadi guru memesona abad 21? Terkhusus, guru sejarah kasus ini sangat penting karena dalam pembelajaran luring sangat sedikit dijumpai guru sejarah yang memesona, apalagi dalam situasi daring, guru sejarah yang memesona abad 21 tidak akan pernah ada. Menyambung pernyataan di atas, kondisi pembelajaran daring dengan tipe guru konvensional dalam mengajarkan pelajaran sejarah dikhawatirkan akan mencetak generasi penerus yang lupa akan sejarah, dan yang lupa memaknai peristiwa sejarah. Dan jangan lupa juga bahwa, saat ini peserta didik "kita" didominasi oleh generasi Z. Generasi ini suka akan kondisi fleksibel, akrab dengan teknologi dan informasi yang dapat mereka akses secara bersamaan. Mereka adalah "generasi digital" yang mahir dan gandrung akan teknologi informasi dan berbagai aplikasi komputer. Lalu bagaimana langkah yang dapat dilakukan untuk menjadi guru memesona abad 21 meskipun dengan sistem pembelajaran jarak jauh (daring) ?

\section{PEMILIHAN PLATFORME-LEARNING}

E-learning adalah sistem pendidikan yang menggunakan aplikasi elektronik untuk mendukung belajar mengajar dengan media jaringan komputer lain (Wulandari \& Rahayu, 2010: 72). Saat ini banyak platforme-learning yang dapat dimanfaatkan untuk pembelajaran jarak jauh (daring) mulai dari yang sederhana seperti WhaatApp (meskipun bukan salah satu platform $e$ learning) hingga platform yang lebih kompleks seperti Google Classrom, Quppier, Rumah Belajar, Ruang Guru dan Moodle (Ika Handarini, 2020:498). Pemilihan platform e-learning sangat penting karena dalam proses daring arena guru ada pada e-learning, pemilihan $e$ learning yang tepat serta ditunjang brainware yang maksimal akan membuat $e$ learning menjadi arena belajar yang menyenangkan bagi siswa. Dari platform yang disebutkan di atas, memilih Moodle menjadi salah satu opsi, karenaMoodle dapat mengakomodir pelaksanaan pembelajaran berupa absensi mandiri, konten materi pembelajaran berupa tulisan, video, audio, proses diskusi, dan proses evaluasi. Contoh, pemberian materi berupa bacaan atau video bukan merupakan barang baru, namun lewat Moodle guru dapat berinovasi dengan mencantumkan konten materi dalam bentut podcast (hasil kolaborasi siswa-guru). Materi pembelajaran sejarah sangat relevan diubah ke dalam podcast sehingga memberikan warna baru dalam proses pembelajaran daring. Guru dan siswa dapat berkolaborasi membuat podcast mengenai salah satu materi yang dirasa menarik lalu menunggahya ke Moodle. Dengan fitur-fitur yang menunjang tersebut saatnya guru sejarah berubah dari guru biasa menjadi guru 
memesona adab 21. Bukankah peserta didik saat ini didominasi oleh generasi $\mathrm{Z}$ yang gandrung dengan teknologi, dan salah satu hal yang dapat membuat mereka terkesan adalah guru harus mampu membuat konten yang menarik minat peserta didik dan dapat diakses secara fleksibel (melakukan kegiatan lebih dari satu) namun tetap bertanggung jawab.

Gambar 1 Tampilan Moodle SMK N 1 Mas Ubud

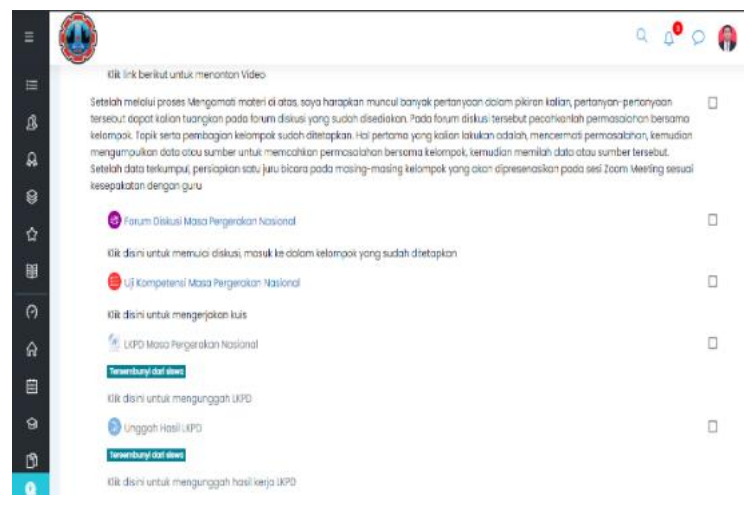

Contoh Aktifitas pembelajaran pada Moodle mandiri SMK N 1 Mas-Ubud Mata Pelajaran Sejarah Indonesia

(Sumber: Dokumentasi Pribadi, 2021)

\section{METODE PEMBELAJARAN}

Sebelum masa pandemi Covid 19 dengan sistem pembelajaran luring, metode dalam penyampaian pembelajaran sejarah di kelas akrab dengan metode Inkuiri, Discovery, Problem Solving dan lainnya sesui dengan karakteristik serta lingkungan belajar siswa, namun ketika dihadapkan pada situasi seperti saat ini, dengan model pembelajaran daring apakah metode tersebut memberikan hasil maksimal dalam proses pembelajaran? Pemilihan metode yang disebutkan diatas harus disesuaikan dengan iklim belajar yang sedang berlangsung, misalnya saja guru memilih metode discovery learning pada salah satu materi, idealnya sintak-sintak pembelajaran discovery learning tersebut disesuaikan dengan sistem pembelajaran daring bukan sekedar mencantumkannya pada RPP tetapi dalam implementasinya hanya mengunakan
WhatsApp grup dalam proses pembelajaran, sehingga terjadi "penyederhanaan" langkalangkah pembelajaran yang tidak menggambarkan metode discovery learning.Proses pembelajaran berlangsung satu arah hanya dari guru ke siswa, tidak ada interaksi antara guru-siswa dan sebaliknya, sehingga menjauhkan peserta didik dari kompetensi yang seharusnya mereka tumbuh kembangkan yang dikenal dengan istilah "4C" jauh dari harapan. Oleh sebab itu dirasa perlu untuk mencoba terobosan baru dengan mengaplikasikan salah satu metode blended learning dalam proses pembelajaran daring (Miyarso, 2019: 77). Model pembelajaran blended learning memadukan sistem pembelajaran tatap muka virtual dengan e-learning. Dengan mengadopsi model blended learning dapat memberikan warna baru dalam pembelajaran daring khususnya dalam pengajaran sejarah. Secara singkat pengaplikasian model blended learning dalam pembelajaran sejarah tersaji pada tabel 1.1 berikut.

\begin{tabular}{|c|c|}
\hline $\begin{array}{c}\text { Kegiatan Guru dan } \\
\text { Siswa saat Virtual Meet }\end{array}$ & $\begin{array}{l}\text { Kegiatan Guru dan } \\
\text { Siswa pada LMS }\end{array}$ \\
\hline $\begin{array}{l}\text { Pendahuluan } \\
\text { - Guru dan siswa } \\
\text { masuk ke dalam } \\
\text { Zoom }\end{array}$ & $\begin{array}{l}\text { Upload bahan materi } \\
\text { oleh Guru }\end{array}$ \\
\hline $\begin{array}{l}\text { tepat waktu. } \\
\text { - Guru bersama } \\
\text { siswa saling } \\
\text { memberi dan } \\
\text { menjawab salam } \\
\text { serta } \\
\text { menyampaikan } \\
\text { kabarnya masing- } \\
\text { masing. } \\
\text { Kelas dilanjutkan } \\
\text { dengan berdoa. } \\
\text { - Siswa menyimak } \\
\text { apersepsi }\end{array}$ & $\begin{array}{l}\text { Implemntasi } \\
\text { PPK, 4C dan } \\
\text { kegiatan } 5 \mathrm{M} \\
\text { secara implisit }\end{array}$ \\
\hline $\begin{array}{l}\text { Kegiatan Inti } \\
\text { - Guru bersama } \\
\text { siswa keluar dari } \\
\text { Meet dan masuk } \\
\text { LMS } \\
\text { - Guru dan siswa } \\
\text { bersama masuk } \\
\text { Virtual Meet } \\
\text { Presentasi virtual } \\
\text { oleh perwakilan }\end{array}$ & $\begin{array}{l}\text { Proses kegiatan } 5 \mathrm{M} \\
\text { berjalan Mengamati } \\
\text { materi, saling menanya } \\
\text { lewat forum diskusi, } \\
\text { mengumpulkan } \\
\text { informasi dari berbagai } \\
\text { sumber, mengolah } \\
\text { informasi yang di } \\
\text { peroleh bersama } \\
\text { kelompok dan proses }\end{array}$ \\
\hline
\end{tabular}




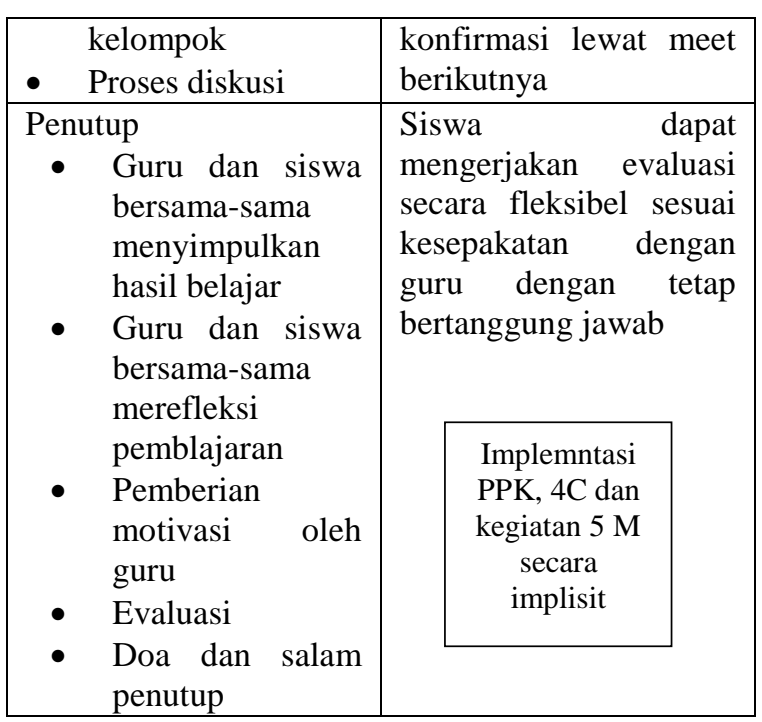

Sintak singkat model pembelajaran blended learning pada mata pelajaran sejarah dengan pendekatan $5 \mathrm{M}$, sintak tersebut belum disisipkan materi hanya sebagai contoh

(Sumber: Dokumen Pribadi, 2020)

Dengan menerapkan model di atas secara konsisten pada mata pelajaran sejarah di masa pandemi saat ini, pembelajaran sejarah akan jauh lebih bermakna, pendekatan 5M yang dirasa mustahil dilakukan dapat diimplemntasikan secara maksimal dengan model tatap muka virtual dan memadukan $e$ learning. Sehingga pada proses tatap muka virtual, guru tetap dapat menanamkan nilainilai karakter kepada siswa seperti tepat waktu, berdoa, menjaga kerapian penampilan dan pada e-learning guru dapat menanamkan nilai karakter siswa seperti bertanggung jawab, komunikatif, saling menghargai. Jika model pembelajaran tersebut dapat dijalankan secara konsisten dan maksimal maka "gelar" guru memesona abad 21 semakin dekat, tidak hanya "gelar" guru memesona abad 21, tetapi akan berimbas juga kepada penanaman

kompetensi abad 21 peserta didik " $4 \mathrm{C}$ " yang tidak terputus akibat pandemi covid 19.

\section{DIGITALISASI TUGAS}

Banyak guru beranggapan bahwa digitalisasi tugas hanya sebatas mengubah tugas yang awalnya berbentuk hard copy ke dalam bentuk soft copy kemudian tugas dikirim. Contonya seorang guru memberikantugas kepada siswa dengan intruksi mengerjakan salah satu latihan soal kemudian hasilnya di kirim dalam bentuk format foto atau dokumen. Secara sederhana digitalisasi dapat dikategorikan sesuai kegiatan yang di jelaskan di atas, namun sadarkah para guru dengan monotonnya pengumpulan tugas seperti di atas, maka akan berimbas kepada kejenuhan dari peserta didik. Sesungguhnya yang dimaksud digitalisasi tugas adalah mengemas tugas yang diberian dengan mengintegrasikan ke dalam aplikasi agar tugas tersebut tidak hanya memiliki nilai edukatif tetapi juga memiliki nilai estetika. Guru dapat memperkenalkan kepada peserta didik berbagai aplikasi yang awalnya hanya diperuntukan untuk hiburan namun bermanfaat dalam ranah pendidikan. Seperti misalnya aplikasi Anchot, Canva, Kinemaster dan lainnya (Muhtadi, 2019: 80). Aplikasi-aplikasi tersebut tidaklah terlalu membebani smartphone peserta didik dibandingkan dengan aplikasi Mobile Legend, COC, dan PUBG. Justru dengan model penugasan yang mengkolaborasikan aplikasi tersebut dapat menambah minat siswa untuk berusaha. Anchor merupakan salah satu aplikasi yang dapat dipergunakan untuk membuat podcast sederhana dan tersedia gratis, dengan mengenalkan aplikasi tersebut kepada peserta didik, guru dapat membentuk kelompok dan mengarahkan siswa untuk menggarap satu podcastsecara bersama, semisal podcast sekitar Proklamasi. Dengan metode demikian kiranya secara tidak langsung guru sudah menumbuh kembangkan kompetensi 4C (khususnya communication, dan collaboration) dalam pembelajaran.

Gambar 2 Podcast pembelajaran daring Contoh podcast pembelajaran daring yang dibuat untuk memotifasi siswa dalam belajar (Sumber: Podcast pribadi, 2020)

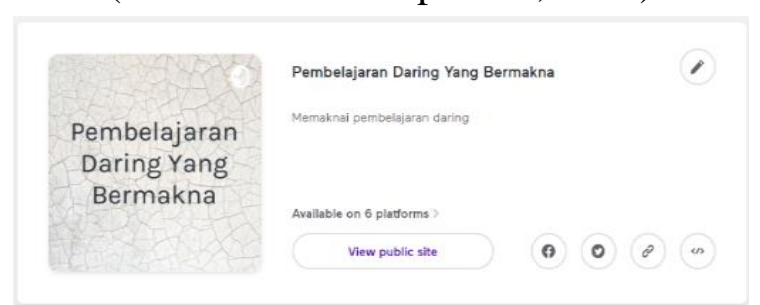


Lain halnya Canva, aplikasi ini dapat dipakai untuk membuat poster, guru dapat mengarahkan peserta didik untuk membuat poster-poster ajakan yang relevan dengan situasi saat ini, seperti poster menjaga kesehatan atau bahaya Covid 19 misalnya. Lalu apa hubnanya dengan materi sejarah? disinilah peran guru memesona abad 21, bagaimana memadukan isu-isu global dengan tetap memperhatikan lokalitas peserta didik.

Gambar 3 Poster karya peserta didik

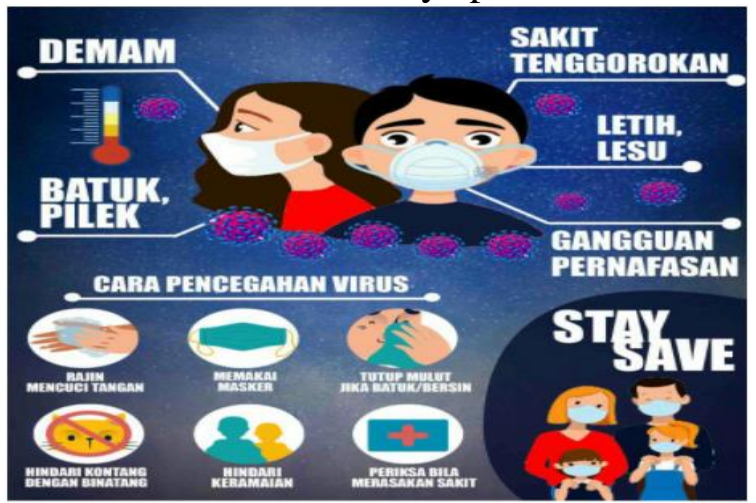

Contoh poster karya salah seorang siswa kelas X MM

(Sumber: Website SMK N 1 Mas Ubud, 2020)

Guru dapat menarasikan bahwa salah satu upaya yang dapat kalian lakukan untuk mengisi kemerdekaan adalah mematuhi intruksi pemerintah dengan tetap mematuhi protokol kesehatan pencegahan Covid 19. Terlebih lagi jika hasil karya peserta didik tersebut dipublikasikan dan dipajang di tempat-tempat umum sebagai himbauan penting 3M, maka akan menambah motivasi siswa bersangkutan atau bahkan temantemanya untuk berkarya. Bukankah peserta didik kita didominasi oleh generasi Z, maka pembelajaran akan lebih bermakna jika generasi digital ini, diberikan dunia mereka yang tak terbatas berselancar di dunia maya untuk mengekpesikan tugas mereka, namun tetap bertanggung jawab serta dalam pengawasan orang tua dan guru.

\section{KOMPETENSI KEPRIBADIAN JARAK} JAUH

Kompetensi ini menyangkut kemampuan personal seorang guru yang mencerminkan kepribadianyang mantap, stabil, dewasa, arif dan berwibawa, menjadi teladan bagi peserta didik, dan berakhlak mulia. Kompetensi ini sering guru tampilkan di kelas saat pembelajaran luring dengan mencontohkan perilaku-perilaku positif. Lalu bagaimanan cara guru untuk menampilkannya dalam pembelajaran jarak jauh? Cara sederhana dapat dilakukan guru untuk tetap dapat memberikan pencontohan perilaku positif kepada peserta didik. Semisal dalam memberikan pengumuman pada WhatsApp, bahasa yang digunakan guru haruslah memberikan contoh yang sopan, serta selalu bersedia menjawab pertanyaan dari peserta didik, kemudian pada saat pembelajaran tatap muka virtual guru dapat memberikan contoh berpenampilan rapi, senyum sapa dan salam, dan tidak lupa juga memperhatikan peserta didik dengan menyapa, menayakan kabar serta memperhatikan penampilan mereka, contoh Guru: "selamat pagi anak-anak, senang sekali kita dapat bertemu kembali meskipun lewat tayangan virtual, andi tolong dong tampilkan wajahnya pada vicom, bapak ingin melihat wajak ceria andi pagi ini”,

Gambar 4. Pembelajaran tatap muka virtual Contoh pembelajaran virtual yang dilaksanakan di SMK N 1 Mas Ubud (Sumber: Dokumentasi Pribadi, 202

Tidak lupa juga bumbui pertemuan virtual tersebut dengan kesan humoris agar

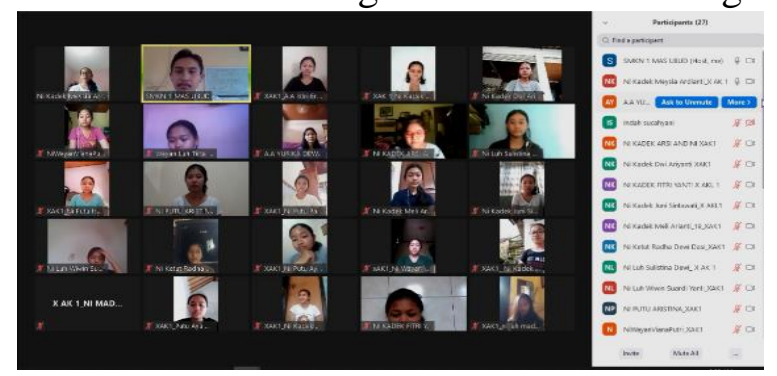

suasana tidak tegang dan peserta didik merasa nyaman untuk belajar. Lewat hal yang dilakukan guru di atas, peserta didik merasa diperhatikan, meski tidak pernah bertemu secara langsung.Tindakan 
sederhana di atas tidaklah sulit untuk dilakukan guru, namun pertanyaanya apakah setiap guru mau menerapkan hal tersebut secara konsisten pada pembelajaran daring saat ini. Sehingga tranformasi guru biasa menjadi guru memesona abad 21 masa pandemi Covid 19 tetap dapat diimplementasikan sehingga apapun situasinya bukankah guru merupakan pelita, segelap apapun, guru harus dapat menyinari dirinya dan murid-muridnya.

\section{SIMPULAN}

Menjadi guru memesona yang memiliki kompetensi abad 21 masa pembelajaran jarak jauh bukan hal yang mustahil. Meski dalam implemntasinya masih dijumpai sarana-prasarana penunjang yang belum memadai. Namun, apakah guru harus menyerah dengan keadaan tersebut. Dalam situasi pembelajaran jarak jauh pemerintah telah memberikan stimulus berupa suntuikan kuota internet kepada guru dan peserta didik, nampaknya hal tersebut menjadi langkah awal untuk memulai tindakan biasa ke arah yang memesona. Sekali lagi sarana-prasarana yang menunjang tidaklah bermanfaat apalagi sampai bermakna jika guru tidak menterjadikanya bermanfaat dan bermakna. Dengan memanfaatkan fasilitas yang ada di abad 21 diharapkan memunculkan guru memesona khussnya guru mata pelajaran sejarah, sehingga tidak ada lagi lahir guru sejarah yang memiliki kompetensi konvensional di tengah-tengah kemajuan teknologi abad 21. Maka sebagai penutup patut direnungkan bersama kalimat Prof I Gde Widja "menjadi guru sejarah, kalian harus siap dengan dua hal. Pertama menjadi guru yang dilupakan siswa, atau yang kedua menjadi guru yang selalu dinanti oleh siswa".

DAFTAR PUSTAKA

Ika Handarini, Oktafia \& Siti Sri Wulandari. 2020. Pembelajaran Daring Sebagai Upaya Study From Home (SFH) Selama Pandemi Covid 19. Surabaya: Unesa.
Jurnal Pendidikan Administrasi Perkantoran (JPAP) Volume 8, Nomor 3, 2020: 496-503 diundih pada file:///D:/Downloads/850327609-1-PB.pdf.

Miyarso, Estu. 2019. Perencanaan Pembelajaran Inovatif. Kemendikbud

Muhtadi, Ali. 2019. Pembelajaran Inovativ. Kemendikbud

Waryanto, N.H. (2006). Online learning sebagai salah satu inovasi pembelajaran. Yogyakarta: Universitas Negeri Yogyakarta. Jurnal Matematika, Vol. 2, No.1, Desember 2006: 10-23 diunduh pada http://staff.uny.ac.id/sites/default /files/132304807/Online\%20Lea rning\%20sebagai\%20Salah $\% 20$ Satu\%20Inovasi\%20Pembel ajaran.pdf

Wulandari, M.S. \& Rahayu, N. (2010). Pemanfaatan media pembelajaran secara online (elearning) bagi wanita karir dalam upaya meningkatkan efektivitas dan fleksibilitas. 